\title{
EL LENGUAJE SOBRE DIOS EN JUAN ESCOTO ERIÚGENA
}

\author{
Ildefonso Murillo \\ Estudio Teológico Claretiano. Madrid
}

El estudio de la concepción del lenguaje sobre Dios de Juan Escoto Eriúgena nos abre a una problemática que comunica a su pensamiento una gran relevancia actual. ¿Podemos hablar de Dios? ¿Cómo hablar de Dios? A principios del Medievo, en el siglo IX, nos encontramos con un pensador que consiguió plantear con rigor y profundidad unos problemas que hoy siguen interesando a quienes reflexionan sobre el tema religioso.

Apoyo mi interpretación casi exclusivamente en dos obras representativas de las dos etapas principales de su evolución intelectual respecto a este punto: De praedestinatione y $D e$ divisione naturae. La primera se caracteriza por una masiva influencia de San Agustín. En la segunda hay que añadir a la inspiración agustiniana el influjo, sobre todo, del Pseudo-Dionisio: de su teología catafática y apofática.

La gran obra de Juan Escoto, síntesis madura de su pensamiento, es De divisione naturae. Nadie se extrañe, por tanto, de que le conceda una atención preferente. Fue redactada entre el año 864 y el 866, después de haber traducido los escritos de Dionisio Areopagita. Sobre todo me fijo en el primer libro por revestir mayor interés que los otros cuatro para el campo de mi investigación.

Desde el comienzo importa advertir también que en la concepción eriugeniana de las posibilidades y limites del lenguaje sobre Dios se refleja una determinada concepción de las posibilidades y límites de la razón humana. Tomo aquí la palabra razón en sentido amplio, de modo que abarca lo que Juan Escoto llama «ratio» y lo que denomina «intellectus».

Este breve trabajo pertenece a una investigación más amplia sobre el problema del lenguaje religioso en el pensamiento medieval. Sin duda, si pudiéramos relacionar las posiciones de nuestro autor con las de otros pensadores medievales, podríamos valorarlas mejor. Pero aquí me limito a presentar una visión de conjunto de su planteamiento y solución del problema, tras aludir con suma brevedad a algunos presupuestos de los que parte y que condicionan su punto de vista. ${ }^{1}$

1 En la bibliografía contemporánea sobre Juan Escoto hay pocas investigaciones que abordan directamente el tema de su teoría del lenguaje sobre Dios. Más o menos indirectamente se toca el tema en estudios que se 


\section{PRESUPUESTOS DE LA CONCEPCIÓN ERIUGENIANA DEL LENGUAJE SOBRE DIOS}

No podríamos comprender en sus justas dimensiones la concepción eriugeniana del lenguaje sobre Dios si no tenemos en cuenta algunos presupuestos. Aludo a los cinco que me parecen más relevantes. Mirados en su conjunto, implican una interpretación general del pensamiento de Juan -Escoto dentro de la cual se inscribe mi exposición de su teoría del lenguaje sobre Dios.

Un primer presupuesto es su situación creyente: el ambiente cultural cristiano de la Francia del siglo IX. En este sentido la perspectiva de interpretación que propuso M. Cappuyns sigue valiendo para captar su verdadero pensamiento. Las rigurosas investigaciones de Jeauneau y Schrimpf nos confirman en esta orientación. Su situación creyente determina profundamente su manera de entender el lenguaje sobre Dios, lo mismo que condiciona su doctrina sobre el hombre y el conocimiento. Cree para entender. Nuestro lenguaje sobre Dios ha de inspirarse en el lenguaje de Dios. Luego expondré con más amplitud este punto.

El segundo presupuesto se refiere a su exégesis filosófica de la Biblia. El objetivo más importante de su obra De divisione naturae es entender la Biblia ${ }^{2}$ mediante el estudio de los Padres y la reflexión racional. Juan Escoto no es un filósofo profano, es decir, extraño a la religión o que reduce ésta a un mito cuyo simbolismo explica. Toda su obra de pensamiento puede entenderse como una exégesis de la Biblia. Pero nos equivocaríamos, si de ahí dedujéramos que carece de interés filosófico. En la Biblia trata de descubrir una concepción racional del Todo. ${ }^{3}$ Quiere aplicar a su interpretación las artes liberales, ${ }^{4}$ donde se remansa toda

refieren a su pensamiento en general o a su concepción del hombre, del conocimiento de Dios, de la razón y la autoridad, de la fe y las teofanías.

Algunos aspectos importantes, a los que sólo aludo de pasada y cuyo esclarecimiento ayuda a comprender mejor lo aquí expuesto, pueden hallarse desarrollados con bastante amplitud en las siguientes publicaciones: C. Allegro: G. Scoto Eriugena. Fede e ragione, Roma, 1974. J.M. Alonso: «Teofanía y visión beata en Escoto Eriúgena», en Revista Española de Teología, 10 (1950) 361-389. W. Beierwaltes:» Negati affirmatio: Welt als Metapher», en Jean Scot Erigène et l'histoire de la philosophie, Paris, 1977, pp. 263-276. W. Beierwaltes: «Language and Object. Reflexions on Eriugena's Valuation of tehe Function and capacities of Language», en Jean Scot Ecrivain, Montreal/Paris, 1986, pp. 209-228. J. Burunat: Fait and Reason in the Thought of John Scotus Eriugena, Nueva York, 1984. M. Cappuyns: Jean Scot Erigène. Sa vie, son oeuvre, sa pensée, Lovaina/Paris, 1933 (Reimpreso en Bruselas, 1969). M. Mc Ginn: «The negative Element in the Anthropology of John the Scot», en Jean Scot Erigène et l' histoire de la philosophie, pp. 315-325. E. Jeauneau: Quatre thémes Erigèniens, Paris, 1978. E. Jeauneau: Etudes Erigèniennes, Paris, 1987. G. Schrimpf: Das Werk des Johannes Scottus Eriugena im Rahmen des wissenschaftsverständnisses seiner Zeit. Eine Hinführung zu Periphyseon, Münster, 1982.

Seul, W., Die Gotteserkenntnis bei Skotus Eriugena unter Berücksichtigung ihrer neuplatonischen und augustinischen Elemente, Bonn, 1932. J. Trouillard: «Erigène et la théophanie créatrice», en The mind of Eriugena, Dublin, 1973.

2 Cor ella se dirige «a quienes quieren entender la Sagrada Escritura -volentibus Sacram Scripturam intelligere- De divisione naturae, edición de Migne, PL, vol. 122, libro IV, cap. 3, columna $746 \mathrm{C}$.

En adelante, cuando cite esta obra, lo haré con la sigla DN añadiendo, sin más, el libro, el capítulo y la columna. Las demás obras las citaré también por la edición de Migne, salvo raras excepciones.

3 Schrimpf, G., das Werk..., p. 246.

4 DN I, 27, 457 A-B; IV 4, 8698 C-870 C. 
la herencia científica y filosófica de la antigüedad griega y latina. Estima particularmente la dialéctica, esta «madre de las artes», ${ }^{5}$ que no es una técnica inventada por los hombres, sino que ha sido inscrita por el Creador en el corazón mismo de las cosas. ${ }^{6}$ En la Biblia pretende hallar lo que satisface plenamente a la razón. . Por esto Eduardo Jeauneau, uno de los mejores conocedores actuales de su pensamiento y de su circunstancia histórica, le llama filósofo exégeta. ${ }^{8}$

No menos importante es un tercer presupuesto: Acuerdo de autoridad y razón. En primer lugar no cabe oposición entre la verdadera autoridad y la recta razón, pues ambas han brotado de la divina sabiduría. ${ }^{9}$ Nuestro autor piensa que «la razón que investiga la verdad de las cosas» no ha de temer ser ahogada por ninguna autoridad, ya sea la de la Biblia, ya la de los Santos Padres y filósofos. ${ }^{10}$ Por supuesto sigue reconociendo la autoridad inapelable de la Biblia, pero esto no quiere decir que su lenguaje sea apropiado cuando habla de Dios, del hombre o de las demás cosas. ${ }^{11}$

Las contradicciones entre la recta razón y la autoridad surgen de una mala interpretación de la Biblia o de una autoridad que no es verdadera autoridad. Lo segundo ocurre a veces con las autoridades humanas de los Santos Padres y de los filósofos. No hemos de olvidar, a fin de superar esos conflictos, las auténticas relaciones existentes entre recta razón y autoridad humana: «La autoridad procedió ciertamente de la verdadera razón, no la razón de la autoridad. Pues toda autoridad que no es aprobada por la verdadera razón parece ser débil -infirma- . Pero la verdadera razón, por defenderse a sí misma en su constancia e inmutabilidad con sus propias fuerzas, no necesita que la robustezca la plena conformidad de ninguna autoridad. Pues la verdadera autoridad no me parece ser otra cosa sino la verdad encontrada por la razón y encomendada por los Santos Padres a las letras para provecho de la posteridad». ${ }^{12}$ Ahora podemos comprender por qué Juan Escoto prefiere acudir antes a la razón que a la autoridad humana en la solución de los problemas. ${ }^{13}$

De todos modos en su método de investigación de la verdad acerca del lenguaje sobre Dios y de las demás verdadades la autoridad de los Padres y de los filósofos juega un papel importante: el de corroborar sus propios razonamientos. El discípulo responde al maestro en De divisione naturae que nada acepta con mayor agrado «que la razón robustecida por una autoridad firmísima». ${ }^{14}$

Un cuarto presupuesto a tener en cuenta son las fuentes neoplatónicas de su pensamiento filosófico. Pero no ha bebido el neoplatonismo en las fuentes griegas originales, sino en el

DN V 4, 870 B.

6 DN IV 4, 749 A.

7 DN V 38, 1010 B-C.

8 Quatre thémes Erigèniens, p. 88.

9 DN I 66, $511 \mathrm{~B}$; V 35, 959 C-D.

10 DN I 63, 508 D-509 A.

11 DN I 64, $509 \mathrm{~A}$.

12 DN I 69, 513 B-C.

13 DN I $69,513 \mathrm{C}$

14 DN I 64, 509 B. 
neoplatonismo teológico de Los Padres, especialmente de Agustín, Dionisio Areopagita y Máximo el Confesor. En pleno siglo IX carolingio realiza una síntesis de dos grandes corrientes neoplatónicas: la agustiniana y la dionisiana. Gracias a Agustín hereda el neoplatonismo de Plotino y Porfirio. Traduciendo y comentando a Dionisio Areopagita y a Máximo, introduce en el mundo latino otro tipo de neoplatonismo emparentado con Proclo.

$\mathrm{El}$ ritmo doble y simultáneo de su universo corresponde fundamentalmente al esquema neoplatónico de la procesión y el retorno. En el sentido descendente asistimos al desarrollo de una teología del símbolo, según la cual Dios se manifiesta en una rica variedad de razones, imágenes y formas sensibles e inteligibles. Manifestaciones de Dios que son superadas en el .orden inverso de su producción, orden ascendente, por medio de la teología negativa. Del mismo modo que Dios es el principio que todo lo ha creado, también es el fin al que todas las criaturas aspiran a retornar, en el que todo ser halla su reposo eterno e inmutable. ${ }^{15}$ Es decir, todas las cosas vienen de Dios y vuelven a Dios.

Y no quiero dejar de aludir, por fin, al presupuesto que está en la base de toda su obra intelectual: su voluntad de verdad. Juan Escoto busca apasionadamente la verdad en sí misma y por sí misma. Las opiniones de otros sólo le interesan por su contribución a la investigación de la verdad. Su actitud nos recuerda a San Agustín. Está inquieto hasta que su espíritu descanse en la verdad absoluta.

¿Por qué busca con tanta pasión la verdad? Porque «no hay peor muerte que la ignorancia, ningún abismo -vorago- más profundo que tomar lo falso por verdadero, lo cual es propio del error». ${ }^{16}$ Escribe en una de sus primeras obras conocidas: «Nadie entra en el cielo sino por la filosofía». ${ }^{17}$ Motivos semejantes expresa otro texto temprano: «Por consiguiente, si no hay ninguna felicidad sino la vida eterna, y la vida eterna es conocimiento de la verdad, no hay ninguna felicidad sino el conocimiento de la verdad... Si no hay ninguna miseria sino la muerte eterna y la muerte eterna es la ignorancia de la verdad, no hay ninguna miseria sino la ignorancia de la verdad. Por tanto donde se ignora la verdad no hay en absoluto vida -ibi nulla $v i t a \rightarrow{ }^{18}$

Describe nuestra situación respecto a la verdad, debido al pecado original, con rasgos negativos: sombras de ignorancia, errores, debilidad de nuestras facultades cognoscitivas, nubes de vanas imaginaciones que no dejan al «ejército de la mente -aciem mentis-» ver a Dios. ${ }^{19}$ No obstante, a pesar de reconocer que para encontrar la verdad necesitamos la ayuda de Dios, ${ }^{20}$ no lo deja todo en manos de Dios. Su filosofía quiere descifrar, con atrevimiento inusitado, el libro del mundo sensible y la Biblia, donde se contiene la manifestación divina de la Verdad.

15 DN II 2, 526 C-D.

16 DN III 10,650 A.

17. Johannis Scotti Annotationes in Marcianum, edición de C. E. Lutz, Cambridge/Mass. 1939, p. 64.

18 De praedestinatione, XVII 9, 430 A-B.

19 DN III 10.649 D-650 A-B.

20. DN III 11, 656 . 


\section{EL LENGUAJE DE DIOS Y EL LENGUAJE SOBRE DIOS}

El presupuesto más importante de su concepción del lenguaje sobre Dios es el lenguaje de Dios acerca de sí mismo: «Sobre Dios ninguna otra cosa han de decir y pensar quienes viven casta y piadosamente y buscan con celo la verdad, sino lo que se encuentra en la Sagrada Escritura; y quienes creen en Dios y disertan sobre tal tema, en lo que creen y disertan, no han de emplear más significaciones y metáforas que las de la Escritura. Pues sobre la naturaleza inefable ¿quién se atreverá a decir que ha encontrado algo por sí mismo, excepto lo que ella misma ha formulado sobre sí misma por sus instrumentos santos o teólogos? $»{ }^{21}$ Dicho en resumen: el lenguaje de Dios sobre sí mismo ha de regular nuestro lenguaje sobre Dios.

Las teofanías ${ }^{22}$ de la creación sensible y de la Biblia nos ofrecen el mejor modelo para entender el lenguaje humano sobre Dios. La naturaleza divina se manifiesta, está y se crea en ellas, pero no se identifica con ellas. ${ }^{23}$ En consecuencia, al hablar de Dios, el lenguaje afirmativo o positivo, como luego expondré, necesita la corrección del lenguaje negativo.

No se ha de aceptar la autoridad de la Biblia como si en ella hubiera un lenguaje propio sobre Dios. Hay que tomar conciencia de que «no ha sido hecho el espíritu humano por causa de la divina Escritura, de la que no necesitaría en absoluto si no hubiera pecado, sino que la santa Escritura fue compuesta con sus símbolos y doctrinas en función del espíritu humano». ${ }^{24}$ Es la razón por la que su lenguaje ha adoptado un carácter simbólico o metafórico: a través de las criaturas se refiere al Creador. Los sentidos de la Biblia vienen revestidos de metáforas y figuras, de expresiones imaginarias, tomadas de la naturaleza sensible, de las que hay que saber despojarlos. ${ }^{25}$

\section{DN I 64, 509.}

22 Una amplia y rigurosa información sobre la concepción eriugeniana de teofanía puede lograrse con la lectura del artículo de Joaquín María Alonso citado en la nota primera y los dos siguientes artículos de Jean Trouillard: «Erigène et la théophanie créatrice» en The mind of Eriugena, Dublin, 1973, pp. 98-113) y «La notion de théophanie chez Erigène» en Manifestation et révèlation, Paris, 1976, pp. 15-39). Se amplía el concepto tradicional de teofanía para incluir la deificación -theiosis-, haciendo una síntesis de Agustín y Máximo el Confesor.

La manera como Juan Escoto concibe la teofanía establece entre Dios y quien le ve una barrera infranqueable. No contemplamos ni podremos contemplar nunca la esencia divina. Ni siquiera el hombre glorificado (deificado) ni los ángeles la ven en sí misma. Sólo el Verbo hecho carne, en virtud de la unión hipostática, goza de este privilegio. (DN I 8, 447 C-448 C; V 23, $905 \mathrm{C}$ ).

23 DN I 13, 455 A; III 23, 689 A-C; V 38, 1010 C-D. Las teofanías son lenguaje de Dios que se entiende por analogía con el lenguaje humano: «No decimos incongruentemente que se hace el pensamiento de la mente o decisión o deliberación, es decir, aquel nuestro más íntimo y primer movimiento, de cualquier modo que lo podamos llamar, en el proceso de venir, como indicamos, al pensamiento, de recibir ciertas formas de fantasías (representaciones) y de expresarse luego en signos de voces o movimientos sensibles significativos -in signa vocum seu sensibilium motuum indicia-, ya que la configuración, que se alcanza en las fantasías, carece por sí misma de toda forma sensible. Pues lo mismo sucede cuando decimos que la esencia divina, la cual subsistiendo por sí misma supera todo entendimiento, se crea en las cosas que han sido hechas desde ella, por ella, en ella y para ella, a fin de que quienes la buscan con adecuado esfuerzo la conozcan en aquellas cosas o por el entendimiento, si son sólo inteligibles, o por los sentidos, si son sensibles» (DN I 12, 454 C-D).

24 Expositiones II 1, $146 \mathrm{C}$.

25 DN I 64, 509 A; III 29, 706 A-B. 
El lenguaje de Dios no se limita a la Biblia. Las cosas sensibles de nuestro mundo nos hablan también de Dios. ${ }^{26}$ Juan Escoto llega a escribir: «No hay nada visible y corporal que no signifique algo incorporal e inteligible». ${ }^{27}$

Nuestro lenguaje sobre Dios ha de esforzarse por descifrar su propio lenguaje. Debemos preguntarnos, por consiguiente, cómo se revela Dios en la Biblia y en el mundo sensible y cuáles son los verdaderos significados del lenguaje divino. En cuanto a la Biblia, el autor no sólo se plantea la cuestión sino que trata de resolverla hablando con detenimiento del significante y del significado de las expresiones bíblicas.

Pero no me quiero detener más en este apartado. Antes de continuar la exposición de la manera como Juan Escoto entiende la naturaleza del lenguaje sobre Dios, conviene que me enfrente con una aparente paradoja. ¿No es Dios inefable? ¿Cómo Juan Escoto, a pesar de repetir con frecuencia esta idea, se atreve a hablar de Dios y afirma que Dios habla de sí mismo?

\section{INEFABILIDAD DE DIOS Y LENGUAJE SOBRE DIOS}

Profundamente influido por la filosofía neoplatónica, Juan Escoto asume su problemática respecto al lenguaje sobre su «más elevado concepto»: sobre el primer principio. Con San Agustín, Dionisio y otros pensadores neoplatónicos supone que el primer principio o Dios es inefable. Pero como a pesar de todo quiere e incluso considera necesario hablar de Dios, dirige todo su ingenio a crear una «razonada expresión» de lo inexpresable. ${ }^{28}$ ¿Cómo hablar de lo inefable?

Juan Escoto nos invita a hablar de lo que no se puede hablar y, utilizando sus propias palabras, con las que él mismo se pone la objeción, «no es inefable lo que se puede expresar de algún modo -quod quodam modo fari potest $\rightarrow{ }^{29}$ Parecería compartir la recomendación que siglos más tarde hará el primer Wittgenstein: «Se debe callar sobre lo que no se puede hablar». ${ }^{30}$

Pero la paradoja o contradicción es sólo aparente. El que la naturaleza divina sea incomprensible e inefable en sí misma no implica que no podamos referirnos a ella con nuestro lenguaje. Las teofanías son la expresión de lo inexpresable. ${ }^{31}$ De modo semejante puede expresarse en nuestro lenguaje el Dios inefable, esa realidad que creemos por la fe, buscamos con la razón y en cuyo conocimiento consiste la vida eterna. ${ }^{32}$ Las palabras «simbólicas» de la fe han sido trasmitidas para que los espíritus piadosos puedan pensar y decir algo sobre la

26 DN III 35, 723 B-724 B.

27 DN V 3,865 D-866 A. Werner Beierwaltes ha analizado este aspecto en su artículo Negati affirmatio: Welt als Metapher, citado en nota 1.

28 Para hacer esta afirmación me he inspirado en el artículo de Werner Beierwaltes «Language and Object», p. 209.

29 DN I 14, $461 \mathrm{~A}$.

30 «Wovon man nicht sprachen kann, darüber muss man schweigen» Tractatus, 7.

31 DN V 26, $919 \mathrm{C}$.

32 DN I 10, 451 B-C. 
realidad inefable e ininteligible o incognoscible, para que los cristianos puedan dar razón de su religión ante quienes se la pidan. ${ }^{33}$

Lo cual no resulta fácil. El maestro le confiesa al discípulo en $D e$ divisionae naturae que sobre este asunto no sabe quién puede hablar breve y claramente. ${ }^{34}$ No es extraño que añada que podemos optar legítimamente por el silencio y que, si nos decidimos a hablar, hemos de ser modestos: hemos de reconocer los límites de nuestras palabras, juicios y razonamientos. Aun ingenios extraordinarios cayeron en el error o volvieron a las cosas inferiores o prefirieron el silencio. ${ }^{35}$

En las teofanías Dios se revela y oculta. Nuestro lenguaje sobre Dios ha de reflejar ese doble aspecto. Por eso hallamos en Juan Escoto una valoración simultánea del lenguaje afirmativo y negativo sobre Dios. En cuanto que es más lo que se oculta que lo que se revela, hemos de preferir el lenguaje negativo.

\section{EL LENGUAJE AFIRMATIVO SOBRE DIOS}

Parece que Juan Escoto no siempre mantuvo la misma posición respecto a la valoración del alcance semántico del lenguaje afirmativo sobre Dios. Cabe distinguir con suficiente fundamento dos etapas en su trayectoria intelectual: la que se nos muestra en De praedestinatione y la que cristaliza en De divisione naturae. No son dos etapas radicalmente distintas e independientes. Ya en la primera etapa atribuye un carácter metafórico a nuestras afirmaciones sobre Dios, aunque no a todas ellas.

Antes de traducir las obras de Dionisio Areopagita admite un doble lenguaje afirmativo sobre Dios: uno propio o cuasipropio y otro impropio. El resorte más eficaz de que dispone nuestro lenguaje es la atribución cuasipropia o propia a Dios de lo mejor que poseemos: el ser, la verdad, la virtud, la sabiduría y otros nombres o verbos semejantes. Reconoce que el significado de estas palabras no pertenece a las criaturas más que descolorido 0 , mejor, vaciado de su contenido real. Por ejemplo, el significado de la palabra ser-esse- sólo se cumple verdaderamente en la naturaleza divina. ${ }^{36}$

No obstante, aun en estos casos, nuestro lenguaje es imperfecto. A fin de explicar por qué no se puede decir nada dignamente de Dios, se pregunta: «¿Cómo unos signos sensibles, es decir, ligados a los cuerpos, podrían significar claramente -ad liquidum - aquella naturaleza alejada de todo sentido corporal, que apenas la alcanza la mente más purificada y que sobrepasa todo entendimiento?». ${ }^{37}$ Nos servimos de ellos porque no tenemos otro remedio: «De ellos se

33 DN I 13, 456 A-B.

34 DN I 13, $458 \mathrm{~A}$.

35 DN III 1, $627 \mathrm{~A}$.

36 De praed. IX $4391 \mathrm{C}$. Son cuasipropios, por significar en nuestra naturaleza lo que es primero y óptimo, sin lo cual no podemos alcanzar la inmortalidad, los verbos «sum», «est», «erat», «esse» y los nombres «essentia», «veritas», «virtus», «sapientia», «scientia», «destinatio» y otros semejantes.

37 De praed IX 1, $390 \mathrm{~B}$. 
vale la pobreza laboriosa del razonamiento humano, después del pecado del primer hombre, a fin de hacer creer e insinuar de algún modo la rica sublimidad del Creador». Y añade: «Por lo demás, si todos los signos del lenguaje no son según naturaleza sino inventados arbitrariamente por los hombres -ex complacito hominum inventa-, ¿qué tiene de extraño el que no basten para expresar aquella naturaleza sólo de la cual se dice verdaderamente que es?».38

Sin embargo ya el primer Juan Escoto sostiene que el significado de la mayoría de los signos; de los que se sirven Dios y el hombre para designar al mismo Dios o su actuación en el universo, es metafórico: «que casi todos los signos o de nombres o verbos y de las otras partes de la oración no pueden decirse propiamente de Dios -omnia paene sive nominum, sive verborum, aliarumque orationis partium signa proprie de Deo dici non posse- $\rightarrow{ }^{39}$ Atribuimos a Dios ese significado ajeno a su naturaleza por semejanza, oposición o diferencia. Decimos, por ejemplo, que Dios nos hizo con su manos o nos ve con sus ojos no porque Dios esté dotado de tales órganos corporales sino por cierta semejanza de lo que tales órganos realizan con la actuación de Dios.

Pasemos a la segunda etapa. Después de traducir y comentar las obras de Dionisio Areopagita, sin renunciar a estos puntos de vista, sus formulaciones son más radicales. Juzga que el lenguaje afirmativo sobre Dios, tanto el que emplea Dios en la Biblia como el que utilizan los teólogos y filósofos, es siempre metafórico. ${ }^{40}$ Acepta como principio fundamental de su teología afirmativa que nada se puede decir propiamente de Dios, sino sólo metafóricamente. Lo cual es así, porque Dios supera todo entendimiento, todas las significaciones sensibles e inteligibles de nuestro lenguaje. ${ }^{41}$

Por tanto, aunque todo cuanto existe, desde lo más elevado hasta lo más bajo, se puede .afirmar de Dios con alguna razón -«non irrationabiliter»-, ningún nombre o verbo puede aplicarse a El en sentido propio. ${ }^{42}$ Cuando llamamos a Dios sol, luz, viento, nube, tempestad, agua, tierra, piedra, viña, cedro, olivo, lirio, hombre, león, oso, águila, paloma, pez y otros innumerables nombres tomados de la naturaleza creada, hay que entender su significado en sentido metafórico.

Dentro de esa perspectiva dedica una amplia atención a mostrar en qué sentido pueden 0 no pueden afirmarse de Dios las diez categorías: los diez géneros universales en que Aristóteles, «el más perspicaz de los griegos - acutissimus apud Graecos-», divide la innumerable variedad de todas las cosas «que son después de Dios y que han sido creadas por

38 De praed. IX, 1, 390 B-C.

39 De praed. IX 1, $390 \mathrm{~B}$.

40 No estoy de acuerdo en este punto con Hermann Dörries (Zur Geschichte der Mystik. Erigena und der Neuplatonismus, Tübingen, 1925, p. 22). El Texto que cita (DN III 19,681 A) no quiere decir que el hombre puede conocer propiamente o no metafóricamente la naturaleza divina, sino que se la conoce verdaderamente a través de las teofanías, pero las teofanías, tal como Juan Escoto las concibe, no se identifican con la naturaleza divina.

Para designar la idea de metafórico, se emplean varias expresiones: metaphorice, translate, figurate, symbolice, non proprie, y algunas otras (Cfr. DN I 13, 456 A, 458 C; 14, $460 \mathrm{~B} ; 37,480 \mathrm{~B} ; 62,504$ A; 67, 512 A; 76, $522 \mathrm{~A}, \mathrm{~B} ; 78,524 \mathrm{~A}$, etc.).

41 DN I 66, $510 \mathrm{~B}$.

42 DN I 66, 511 A-67, 512 A. 
El». ${ }^{43}$ Estas sólo valen para significar con propiedad las criaturas y sus movimientos. En el caso de Dios, «aquella naturaleza que no puede decirse ni entenderse», su poder significativo «falla totalmente -per omnia in omnibus deficit- $\gg{ }^{44} \mathrm{Si}$ alguna categoría se afirmara propiamente de Dios, esto querría decir que Dios es género o especie o accidente, lo cual va «contra la pura contemplación de la verdad», contra la recta razón. ${ }^{45}$ Por consiguiente, «realmente ni Dios actúa, ni sufre, ni mueve, ni es movido, ni ama, ni es amado», ${ }_{4}^{46}$ aunque parezca que esto no respeta la autoridad de la Biblia y de los Santos Padres. Pues supongamos que Dios actuara; entonces habría que distinguir en El entre sustancia y accidentes, ya que en los seres que actúan una cosa es el agente, otra el poder actuar y otra el actuar. ${ }^{47}$ Acude a la autoridad de San Agustín en apoyo de sus razonamientos: «Como dice el santo padre Agustín en los libros sobre la Trinidad, cuando se llega a la teología, esto es, a la investigación de la sustancia divina, desaparece completamente el valor de las categorías». ${ }^{48}$

Y pensando así no se siente Juan Escoto en desacuerdo con el sentido último de la Biblia. Aun reconociendo que en ella se esconde la verdad, no se ha de creer que la misma emplee siempre «los signos propios de los verbos o nombres, manifestándonos la naturaleza divina; sino que utiliza ciertas semejanzas y varios modos de verbos y nombres metafóricos (tomados de la naturaleza creada para significar la naturaleza divina), condescendiendo con la humana debilidad y despertando con doctrina sencilla la atención de nuestros sentidos todavía rudos e infantiles». ${ }^{49}$

Ni siquiera se libran de ese carácter metafórico las palabras que designan las llamadas «perfecciones puras» o realidades más elevadas que conocemos: ser, bondad, verdad, sabiduría y otras semejantes. ${ }^{50} \mathrm{El}$ ámbito de lo metafórico abarca todo lo que conocemos con los

43 Comienza a tratar sobre èsto en DN I 14, 462 D y no cesa de hacerlo hasta el último párrafo del libro primero. Lo que expone esporádicamente en los otros libros, salvo raras excepciones, no reviste ya especial novedad.

44 DN I 15, 463 B.

45 DN I 36, 480 A-B.

46 DN I 62, 504 B. Tampoco se exceptúan las expresiones en que afirmamos que Dios ama (DN I 68, 512 D-513 A). Los verbos que utiliza la Biblia o de que se valen los teólogos y filósofos no significan más que metafóricamente la divina esencia incomprensible e inefable: «Por ejemplo, cuando oímos que Dios quiere y ama 0 aprecia, ve, oye y demás verbos, que pueden predicarse de El no conviene que pensemos otra cosa sino que con significaciones connaturales a nosotros aboga por su misma inefable esencia y virtud.... Ser y querer y hacer y amar y apreciar y ver y otras expresiones semejantes que pueden predicarse de El, como dijimos, no otra cosa indican de Dios sino que todo esto ha de ser aceptado en El mismo como lo único y lo mismo e insinúan su esencia inefable de aquel modo en que se deja significar» (DNI 73,518 C-D). Por extenderse el sentido metafórico a todos los significados de nuestro lenguaje, abarca todos los verbos «que significan todos los movimientos de toda la criatura mutable: o naturales 0 no naturales (odiar, emborracharse, enloquecer...) 0 intelectuales o racionales 0 irracionales o corporales o no corporales o locales o temporales, rectos, oblicuos, angulares, circulares, esféricos» (DN I 68, 513 A).

47 DN I 62, B-63, 508 D.

48 DN I 15, 463 B.

49 DN I 64, $509 \mathrm{~A}$.

50. DN I 13,456 A-457 D. Acerca del verbo ser escribe: «Por lo cual, al decir que Dios es, no decimos que sea de algún modo. Y por esto decimos que es y era simplemente e infinitamente y absolutamente en sí mismo. Pues lo divino es incomprensible a toda razón y entendimiento y, por esto, al predicar de El el ser, no decimos 
sentidos o con nuestra razón y entendimiento ${ }^{51}$ hasta el mismo nombre de Dios y cuanto decimos o pensamos sobre la Trinidad. ${ }^{52}$ En estas doctrinas notamos la huella de Dionisio Areopagita.

A pesar de todo, sin embargo, el lenguaje designa la realidad, aun tratándose de Dios. Juan Escoto no se queda cautivo en el lenguaje, como sucede en algunos pensadores contemporáneos. Y logra evitar esto porque las metáforas de su lenguaje afirmativo están sólidamente apoyadas sobre la causalidad universal de Dios. ${ }^{53}$.

Igual que cualquier otra causa, Dios puede ser significado con cierta verdad por sus efectos creados, pues éstos participan de El y subsisten en El. La acción creadora determina el significado fundamental del lenguaje afirmativo en la teología de Juan Escoto. No en vano la creación es concebida como manifestación de Dios en las cosas creadas - «Creatio, hoc est in aliquo manifestatio». ${ }^{54}$ Lo mismo que el mundo sirve para que Dios se conozca y se haga conocer de las criaturas racionales, ${ }^{55}$ también sirve para que los hombres podamos referirnos a El con nuestro imperfecto lenguaje. Imperfección que no nos impide significar las perfecciones divinas, fuente de las perfecciones creadas.

El discípulo pregunta al maestro por qué llama con el mismo nombre de naturaleza al universo creado y al Creador. Responde el maestro: «De ningún modo pondría al Creador en las divisiones del universo creado. Pero juzgué que debía ponerlo en las divisiones del mismo universo que se comprende con la única palabra naturaleza en sentido universal no por una sino por muchas razones. Pues con el nombre de naturaleza no sólo se suele significar el universo creado sino también a su Creador. La primera y suma división de la naturaleza universal es en creadora del universo creado y en creada en el mismo universo creado. División que puede guardarse en todas las universalidades (bien, esencia, vida, sabiduría, virtud) indefinidamente de modo uniforme. Pues la primera división del bien universal es en el bien único, sumo, inmutable por sí y sustancial, del que todo bien mana, y en el bien que es por participación del bien sumo e inmutable. Igualmente es la misma la división principal de la esencia universal, de la vida universal, de la sabiduría universal, de la virtud universal... ¿Ves cómo el Creador

que El sea. De El procede el ser, pero El mismo no es ser. Pues de algún modo es sobre el ser y sobre lo que universalmente se dice y se entiende» (DN I 39, 482 A-B).

51. DN I 36, 480 A-B.

52 Al hablar de la «naturaleza que crea y no es creada», principio, medio y fin de todo (DN I 11, $451 \mathrm{D}$ ), se detiene a analizar el significado positivo del nombre Dios, que se usa muchísimo en la Biblia, donde no sólo se llama Dios a la esencia divina, «sino también a aquel modo según el cual se manifiesta en cierta manera a las criaturas intelectuales y racionales» (DN I 7, $446 \mathrm{D}$ ). Discurre ampliamente sobre la etimología de este nombre (DN I 12, 452 C-454 D).

Sobre la Trinidad nos advierte: «todo lo que se dice o se piensa o se entiende de la Trinidad de la simplicísima bondad son ciertos vestigios y teofanías de la verdad, pero no la misma verdad» (DN II 35, 614 C). Meras teofanías de la verdad son en primer lugar los nombres Padre, Hijo y Espíritu Santo (DN I 13, 456 A-457 D).

53 DN I 13, 458 B; 15, 463 B-C; 66, 510 D-511 A; 78, 524 A-B.

54 DN I 13, 455 .

55. DN I 12, 454 A; II 23, 689 A-B. 
de todo el universo ocupa el primer lugar en todas las divisiones? No sin razón, pues es el principio de todas las cosas e inseparable de toda la diversidad que creó, sin lo cual no puede subsistir como Creador» ${ }^{56}$

El contenido de esta larga cita nos puede desconcertar. ¿No nos dijo antes Juan Escoto que los nombres de todas las perfecciones sólo se pueden predicar de Dios en sentido metafórico? ¿Cómo nos habla ahora de naturaleza universal, bien universal, vida universal, etc? ¿No existe una clara contradicción entre la posición que expone en el libro primero y la que defiende en el tercero? Más bien se trata de dos posiciones complementarias. En el primer libro analiza nuestro lenguaje sobre Dios desde las criaturas, mientras que en el tercero lo mira desde el Creador. No habría, por tanto, apenas divergencia entre el primer Juan Escoto y el segundo. Este último no niega que algunas perfecciones se puedan atribuir a Dios de manera propia. Lo único que niega es que las perfecciones de Dios se identifiquen con las de las criaturas: que las perfecciones categoriales de las criaturas se puedan aplicar no metafóricamente al Creador. ${ }^{57}$ Se hace sentir la falta de la noción de analogía, con cuya presencia hubieran desaparecido muchas aparentes paradojas en el lenguaje eriugeniano sobre Dios.

\section{EL LENGUAJE NEGATIVO SOBRE DIOS}

La obra De divisione naturae comienza dividiendo la totalidad de las cosas, a la que llama naturaleza, en dos porciones: la de las cosas que son y la de las que no son. ${ }^{58}$ Por cosas que no son suele entenderse en la segunda etapa las que «debido a la excelencia de su naturaleza» superan la capacidad de nuestros sentidos, razón y entendimiento..$^{59}$ Que Dios pertenece a las cosas que no son quiere decir, pues, que está más allá de las capacidades de nuestro conocimiento y lenguaje. ${ }^{60}$ En la primera etapa no podía concebir Juan Escoto todavía que se hablara del no ser de Dios, pues lo consideraba contrario a su realidad « «um nihil Deo contrarium sit nisi non esse»-.61 En ese sentido tampoco aceptaría tal expresión en la segunda etapa. Si adopta la expresión el segundo Juan Escoto, es porque su sentido no niega la realidad de Dios sino nuestro conocimiento y lenguaje sobre El. Sólo habría que designar con la palabra ser a las cosas que podemos conocer y expresar en nuestro lenguaje.

Aquí, por razones obvias, me interesa considerar la negación del lenguaje sobre Dios. El tema es muy importante. No aludir a este aspecto supondría descuidar una de las dos dimensiones básicas de la teoría eriugeniana del lenguaje sobre Dios.

\footnotetext{
56 DN III 1, 621 A-B.

57 Me convence plenamente la interpretación que sobre este punto desarrolla Rafael López Silonis en su artículo Sentido y valor del conocimiento de Dios en Escoto Eriúgena, pp. 140-151 (Cfr. nota 1).

Claro que, como sobre las perfecciones de Dios sólo podemos hablar a partir de las perfecciones de las criaturas, en sentido propio nuestro lenguaje sobre Dios siempre sería metafórico.

58 DN I, Introducción, $442 \mathrm{~A}$.

59 DN I 3, 443 A-D. - Homilia, 283 B-C.

60 DN III 16, $667 \mathrm{~A}$.

61 De praed. IX 4, $391 \mathrm{C}$.
} 
La imperfección semántica del lenguaje afirmativo sobre Dios, a la que aludimos en el apartado anterior, necesita el correctivo del lenguaje negativo, con el fin de mostrar su limitación para expresar la naturaleza divina. Por medio de la negación nos alejamos de las imperfecciones de lo creado y nos acercamos a la infinita perfección del Creador: «A Dios se le conoce mejor no sabiendo. La ignorancia de El es verdadera sabiduría. Más verdadera y fielmente se le niega en todo que se le afirma. Cualquier cosa, pues, que niegues de El, la negarás verdaderamente; $s$ in embargo no todo cuanto afirmes, lo afirmarás verdaderamente. $\mathrm{Si}$ probaras que esto o esto es $\mathrm{El}$, ciertamente serás desmentido por falsedad, porque no es nada de todo lo que es: de todo lo que puede decirse o entenderse. $\mathrm{Si}$, en cambio, proclamas que $\mathrm{El}$ no es esto, ni aquello, ni ninguna cosa, parecerás ser veraz, porque no es nada de lo que es y de lo que no es (en el ámbito categórico). Y nadie puede acercarse a El, si antes no abandona todos los sentidos y las operaciones intelectuales y lo sensible y todo lo que es y lo que no es , habiendo reforzado antes el camino de la mente, $y$, en cuanto es posible, se restituye inconsciente a la unidad de aquel mismo que es sobre toda esencia e inteligencia, que no tiene razón ni inteligencia, ni se dice, ni se entiende, ni hay nombre, ni verbo de El». ${ }^{62}$ En resumen, Dios no es ninguna de las cosas «de las que puede decirse o entenderse lo que son-de quibus potest dici vel intelligi, quid sunt-», por ser infinito e innombrable..$^{63}$ Dicho con otras palabras, la intuición fundamental de la teoría eriugeniana del conocimiento de Dios y del lenguaje sobre Dios se resume en el reconocimiento de que Dios es esencialmente incognoscible e inefable. ${ }^{64}$ En la ascensión del hombre a Dios siempre persiste la «oscuridad divina». La trascendencia de Dios supera el poder cognoscitivo del entendimiento humano y la capacidad expresiva de nuestro lenguaje. El lenguaje negativo equivale a la docta ignorancia en el ámbito del conocimiento. Los límites de nuestro conocimiento corresponden a los de nuestro lenguaje.

En los textos de Juan Escoto sobre el lenguaje teológico negativo oímos resonar a San Agustín y a Dionisio Areopagita. Como Dionisio, acentúa el valor del lenguaje negativo. En el prefacio de su traducción de las obras de Dionisio podemos leer estas palabras: «(Dionisio) nos advierte preclarísimamente que por la privación de todo lo que puede decirse y entenderse conviene llegar a la verdad que es causa de todo lo que ha sido creado desde ella, por ella, en ella y para ella, por razón de la excelencia de su esencia». ${ }^{65}$ Lo que se puede entender se puede decir y viceversa. A Dios no se le puede entender ni decir. Por consiguiente el lenguaje negativo es el más apropiado para significarle. La negación nos acerca más a la realidad de Dios que la afirmación. Es un lenguaje negativo por excelencia, no por defecto.

No hay que confundirlo con un lenguaje incapaz de hablar sobre Dios. Decimos que la naturaleza divina no es verdad porque es más que verdad. Lo mismo sucede respecto a la expresión de otras realidades: ser, ciencia, bondad, amor, visión, movimiento, etc. ${ }^{66}$ Mientras

62 DN I 66, 510 B-D.

63 DN II 28, 589 C-D.

64 Lo que Burumat dice respecto del conocimiento de Dios puede aplicarse también al lenguaje sobre Dios

(Faith and Reason..., p. 89).

65 Versio Dionisii, 1036 C-D.

66. DN I 39, 482 A-B; 75, 521 C-522 A; II 35, 614 C. 
que el lenguaje afirmativo se apoya en las criaturas, el negativo se dirige hacia más allá de lo creado: hacia el Creador. ${ }^{67}$ Lo que negamos de Dios, lo negamos verdaderamente.

Saca con lógica implacable las consecuencias de esta valoración del lenguaje negativo. Me limito a enunciar tres de las más importantes. El lenguaje afirmativo ha de utilizarse, al referirnos a Dios, con la prudencia de quien es consciente de sus límites. Las diez categorías de Aristóteles han de negarse cuando se trata de Dios. ${ }^{68} \mathrm{La}$ ignorancia que se expresa en el lenguaje teológico negativo es la sabiduría suprema. ${ }^{69}$

Pero Juan Escoto no concibe los dos lenguajes como incompatibles. Aunque parezcan contrarios entre sí, no se oponen en absoluto, «sino que están de acuerdo en todo -sed per omnia in omnibus sibi invicem consentiunt $\rightarrow \gg .^{70}$ Para mostrar esto pone un ejemplo. Afirmamos que Dios es verdad. Negamos que Dios es verdad. Y parece que nos contradecimos. Mas no sucede tal cosa. Pues, cuando decimos que Dios es verdad, no afirmamos propiamente que la naturaleza divina es verdad, sino que «puede llamarse con tal nombre a modo de metáfora que conduce de la criatura al Creador» ${ }^{71}$ Vestimos con esa palabra a la naturaleza divina, una vez que la hemos desvestido de su significación propia. Cuando, en cambio, decimos que Dios no es verdad, con plena conciencia de que la naturaleza divina es incomprensible e inefable, no negamos su realidad, sino que simplemente decimos «que ni se llama propiamente ni es verdad -veritatem nec vocari proprie, nec esse- $\rightarrow .^{72}$ Es decir, el lenguaje negativo o teología negativa despoja a Dios de todas las significaciones con que el lenguaje afirmativo lo viste. En síntesis: el uno dice que se le puede llamar así, pero no que sea propiamente eso; el otro indica que no es eso, aunque se le pueda llamar así. Ambos lenguajes, por tanto, no se destruyen mutuamente.

El uno y el otro son verdaderos ${ }^{73} y$, en conjunto, representan la medida exacta de nuestro lenguaje sobre Dios, a no ser que deseemos optar por el silencio. ${ }^{74}$ Ambos son imprescindibles: «Y esta es la cauta y católica manera de hablar de Dios: que en primer lugar prediquemos todo de El o nominal o verbalmente según la teología catafática, es decir, la afirmación, pero no propiamente sino metafóricamente, y que, luego, todo lo que prediquemos de El por la teología catafática lo neguemos de su naturaleza por la apofática, es decir, la negación, pero no metafóricamente sino propiamente». ${ }^{75}$ Creo que esto se explica, entre otras razones, porque, tal como supone Allegro, la teología de Juan Escoto «es de hecho el fructuoso encuentro entre la epistemología aristotelizante de Boecio y la teología negativa de Dionisio: Dios sigue siendo el Dios ignorado y conocido, innombrable y nombrable». ${ }^{76}$

67 DN IV 5, $758 \mathrm{~A}$.

68 DN II $2,528 \mathrm{C}$.

69 «DN I 66, 510 B; II 29, 597 D. Ipsa ignorantia summa ac vera est sapientia» (DN II 28, 594 A).

70 DN I 14, $461 \mathrm{C}$.

71 DN I 14, $461 \mathrm{C}$.

72 DN I 14, 461 C-D.

73 DN IV 5, 757 D.

74 DN I 13, A.- Versio Maximi, Praef. 1196 A_B.

75 DN I 76, 522 A-B.

76 G. Scoto Eriugena..., p. 441 (Cfr. nota 1). 
No quiero terminar este apartado sin decir algo sobre las partículas super y plusquam. Juan Escoto considera su introducción en el lenguaje latino como un progreso considerable, pues integran ambos lenguajes: el afirmativo y el negativo. La forma externa de tales expresiones sería afirmativa, pero su significado más profundo sería negativo. ${ }^{77}$ Gracias a ese elemento negativo, que prevalece en su significado, los nombres precedidos de super y plusquam podrían aplicarse propiamente a Dios. ${ }^{78}$

\section{CONCLUSIÓN: ACTUALIDAD DE JUAN ESCOTO ERIÚGENA}

El año 1988 se fundó en Francia la Logia de Estudio e Investigación Juan Escoto Eriúgena. Uno de sus integrantes escribe que eligieron ese nombre porque hallaron en Juan Escoto un buen modelo de las cualidades necesarias a los miembros de una logia de investigación: equilibrio entre razón y espiritualidad, pensamiento libre como condición de creatividad, preocupación por hallar el «buen método» que permita penetrar en el ámbito de la sabiduría, capacidad de «traducción» y de sentido amplio. ${ }^{79}$

Cualidades que no resultan extrañas a quien se interesa por su teoría del lenguaje sobre Dios. Juan Escoto, en un marco cultural muy distinto del nuestro, con una pasión admirable de verdad y en diálogo con otros pensadores, tratando de interpretar la verdad de la Biblia, se plantea a fondo el problema del lenguaje religioso $y$, a la vez, el problema del conocimiento y de la realidad. Su reflexión sobre la naturaleza del lenguaje y sus posibilidades nos muestra con claridad la conciencia que tenía de los límites y alcance de la razón humana.

Hoy creemos saber mucho porque somos capaces de describir con perfección nunca antes alcanzada los cuerpos y su funcionamiento. Pero la verdadera sabiduría se dirige al sentido del Todo. Y sobre el fundamento del Todo, donde se nos plantea el problema de Dios y del hombre, el saber más elevado consiste en reconocer nuestra ignorancia.

Acentuar el carácter adecuado de nuestro lenguaje sobre Dios lleva a callejones sin salida, que están en la base de algunos ateísmos y agnosticismos modernos y contemporáneos. El proceso de complementación mutua entre lenguaje afirmativo y negativo, tal como nos la ofrece Juan Escoto Eriúgena, permite, sin embargo, construir una teología filosófica modesta, abierta a una constante renovación o revisión crítica. Dios queda siempre más allá de nuestro lenguaje.

77 Nos lo muestra con un ejemplo: «Dios es esencia, he aquí la afirmación; Dios no es esencia, he aquí la negación; Dios es superesencial, he aquí simultáneamente la afirmación y la negación. Pues, aunque en apariencia -in superficie- falta la negación, quien dice que Dios es superesencial, no dice qué es, sino qué no es; dice que no es esencia, pero que es más que esencia» (DN I 14, 462 C-D). La superesencia de Dios se designa mejor por la negación que por la afirmación. Al decir que Dios ha hecho todo de la nada, la Biblia quiere indicar que lo ha hecho de su superesencia (DN III 19, 681 C-20,685 A).

78 DN I 14, 460 C-D.

79 Stani Foliguet, «Pourqoi avoir choisi Jean Scot Erigène», en Les Cahiers jean Scot Erigène: 1 Images de l'homme et initiation. Paris, 1988. 